Archive for

Organic Chemistry

Arkivoc 2020, part vi, 1-10

\title{
Synthesis and spectral comparison of electronic and molecular properties of some hydrazines and hydrazyl free radicals
}

\author{
Bianca Patrascu, ${ }^{a}$ Cecilia Lete, ${ }^{b}$ Codruta Popescu, ${ }^{a}$ Mihaela Matache, ${ }^{a}$ Anca Paun, ${ }^{a}$ \\ Augustin Madalan, ${ }^{a}$ and Petre Ionita ${ }^{a} *$ \\ ${ }^{a}$ University of Bucharest, Faculty of Chemistry, Panduri 90-92, Bucharest, Romania \\ ${ }^{b}$ Institute of Physical Chemistry, 202 Spl. Independentei, Bucharest, Romania \\ Email:petre.ionita@chimie.unibuc.ro
}

Received 12-05-2019

Accepted 02-10-2020

Published on line $02-26-2020$

\section{Abstract}

Continuing our work on hydrazyl free radicals, five triphenylhydrazine derivatives, one a new compound, were synthesized to compare the electronic and molecular properties of these compounds, study the influence of substituents on the phenyl rings, and compare their properties with the parent hydrazines and corresponding anions. These hydrazines demonstrate both acid-base and redox properties. The hydrazine proton can be removed by base, yielding the corresponding anion and both the hydrazines and their anions can be oxidized to the corresponding hydrazyl free radicals. ESR spectra confirmed their formation and X-ray crystallography of one compound confirmed their structures.
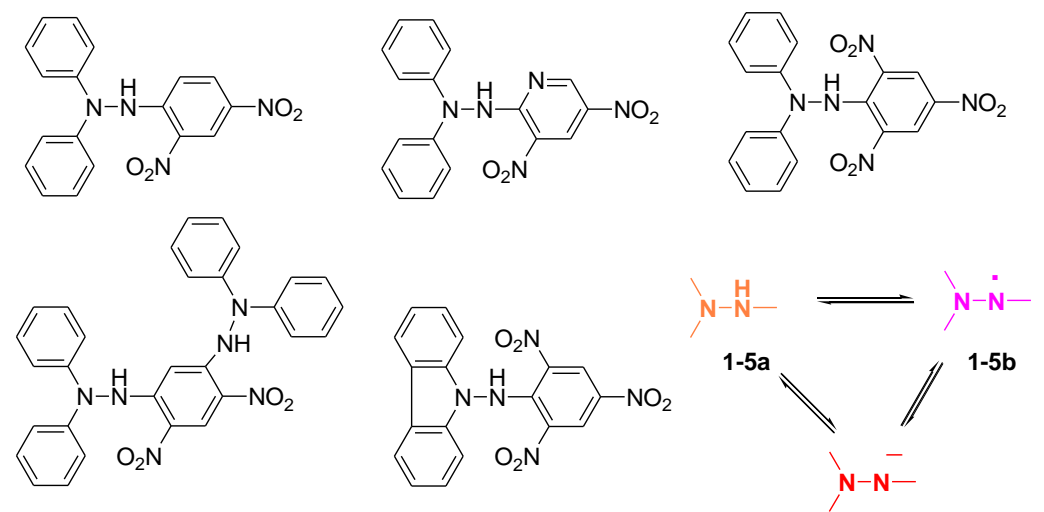

Keywords: Hydrazines, hydrazyl free radicals, ESR, bond dissociation energy, redox, cyclic voltammetry 


\section{Introduction}

Hydrazyl free radicals of the triphenyl type are a class of organic compounds which possess several important characteristics. For example, they show high stability under normal conditions (e.g., they do not react with oxygen and do not dimerize) with lifetimes ranging from persistent (hours or days) to permanent depending on the phenyl substituents. ${ }^{1,2}$ They possess redox properties in that they are able to abstract an electron or hydrogen atom from other compounds). ${ }^{3}$ Their reduced counterparts, hydrazines, have acid-base properties (the hydrazine proton can be removed easily by a base). ${ }^{4}$ These acid-base and redox properties are reversible. ${ }^{5}$ They also have intense colors. ${ }^{6}$ These properties make them useful in acid-base and redox processes that are accompanied by color changes. ${ }^{7}$

The best-known hydrazyl free radical is 2,2-diphenyl-1-picrylhydrazyl (DPPH). It is a stable solid, soluble in organic solvents, with a violet color similar to that of potassium permanganate. It is used as a standard in Electron Spin Resonance (ESR) Spectroscopy, and as a short-lived free-radical scavenger as well as in total antioxidant-capacity measurements. ${ }^{8,9}$ Reduction (e.g., with ascorbic acid) leads to the corresponding yellow hydrazine, which, in the presence of a base, leads to the anion with a red-brown color. All these processes are reversible, as mentioned above.

Continuing our work on hydrazyl free radicals, ${ }^{10}$ we aimed to compare some electronic and molecular properties of these compounds, not only to study the influence of the substituents on the phenyl rings, but also to compare their properties with the parent hydrazines and their corresponding anions. We, therefore, prepared hydrazines $\mathbf{1} \mathbf{a}-\mathbf{5} \mathbf{a}$, which, following oxidation, led to the free radicals $\mathbf{1 b} \mathbf{b} \mathbf{b}$ or, by proton removal, the corresponding anions $\mathbf{1} \mathbf{c}-\mathbf{5} \mathbf{c}$ as shown in Figure 1 . Compounds $\mathbf{3 a}$ and $\mathbf{3 b}$ are commercially available; compounds $\mathbf{4 a}$ and $\mathbf{4 b}$ have not been reported previously).

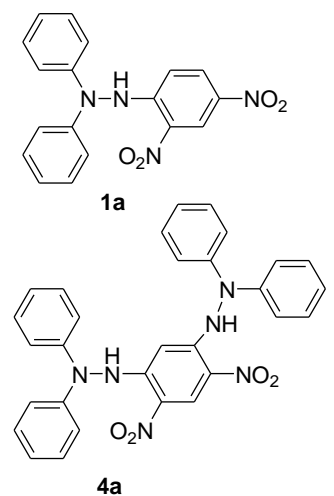

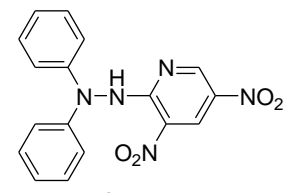

2a

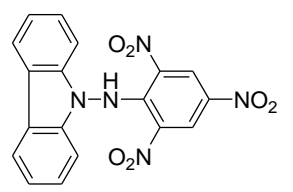

$5 a$

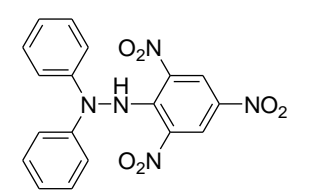

$3 a$

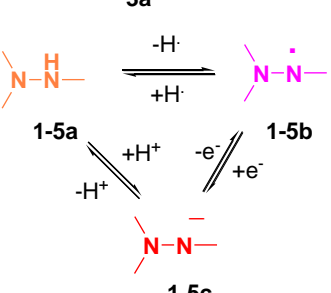

Figure 1. Compounds used in this study, and the reversible conversion between hydrazines (a), hydrazyls (b), and the corresponding anions (c).

\section{Results and Discussion}

\section{Synthesis and structural analysis}

Hydrazines 1a-5a are easily obtained from activated halogeno-nitrobenzenes and the corresponding precursor hydrazines in the presence of a base. Reactions are fast and proceed with good yields (see Experimental Section for details). Although compound $\mathbf{3 a}$ is commercially available, it was synthesized in a single step from 
picryl chloride and 1,1-diphenylhydrazine. All compounds were characterized by ${ }^{1} \mathrm{H}-$ and ${ }^{13} \mathrm{C}-\mathrm{NMR}$ spectroscopy and the results corresponded with the literature data.

Compound $4 \mathrm{a}$ is a new compound and was obtained in a similar way from 1,1-diphenylhydrazine and 1,5difluoro-2,4-dinitrobenzene. In the IR spectrum (Supplementary Material, Figure S1), the $v_{\mathrm{NH}}$ band appears at $3312 \mathrm{~cm}^{-1}$, the aryl $v_{\mathrm{CH}}$ at $3087 \mathrm{~cm}^{-1}$, and NO $\mathrm{N}_{2}$ bands were observed at $1584 \mathrm{~cm}^{-1}$ and $1255 \mathrm{~cm}^{-1}$, respectively. In the ${ }^{1} \mathrm{H}$-NMR spectrum, the two $-\mathrm{NH}$ - protons appear at $9.95 \mathrm{ppm}$, the two $\mathrm{CH}$ protons from the dinitrobenzene rings appear as two singlets at 9.06 and 9.09 ppm, respectively, and the other aromatic protons appear in the 7-7.3 ppm range (Supplementary Material, Figure S2). The ${ }^{13} \mathrm{C}-\mathrm{NMR}$ spectrum is also consistent with the structure (Supplementary Material, Figure S3).

For compound $\mathbf{5 a}$, crystals suitable for X-ray analysis were obtained which provided a reconfirmation of its structure. ${ }^{11}$ It crystallizes in the monoclinic $P 2 \sqrt{ } / a$ space group with two crystallographic-independent molecules in the asymmetric unit (Figure 2; Table S1). The unit cell parameters are comparable with those already reported by Robertson et al. ${ }^{11}$ The two moieties present some similar features. Two nitro groups of the 2,4,6-trinitrophenyl fragments are nearly coplanar with the central benzene ring. In the first type of molecule, X-ray crystallographic structural analysis showed that the planes of the nitro groups containing the N3 and N4 nitrogen atoms form dihedral angles of 1.2 and $12.4^{\circ}$, respectively, with the mean plane of the central aromatic ring. In the second type of molecule, the dihedral angles formed between the planes of the nitro groups containing the N8 and N9 nitrogen atoms and the mean plane of the central benzene ring were 9.5 and $12.2^{\circ}$, respectively. The third nitro group in both of the crystallographic structures of the molecules is significantly out of the mean plane of the central benzene ring with dihedral angles of $59.3^{\circ}(05-\mathrm{N} 5-06)$ and $64.3^{\circ}$ (011-N10-012), respectively.

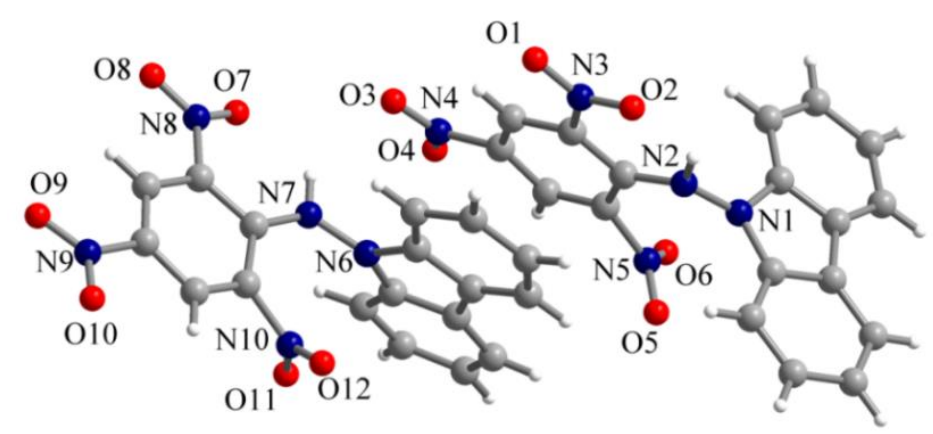

Figure 2. View of the asymmetric unit in the crystal structure of compound 5a along with the $\mathrm{N}$ - and O-atom labeling schemes.

These nitro groups are involved in strong $\pi-\pi$ interactions with the carbazole fragment of the same molecule. The separation between the 05-N5-06 nitro group and the carbazole containing the N1 nitrogen atom is $2.71-3.31 \AA$, whereas the separation between the 011-N10-012 groups and N6 carbazole fragment is $2.70-3.20 \AA$. . In both molecules, the carbazoles make similar dihedral angles with the benzene rings of the 2,4,6-trinitrophenyl fragments $\left(72.9^{\circ}\right.$ and $72.1^{\circ}$, respectively). The $\mathrm{N}-\mathrm{H}$ groups establish intramolecular hydrogen interactions with one nitro group, $\mathrm{N} 2-\mathrm{H} 2 \mathrm{~N} \cdots \mathrm{O} 2=1.94 \AA$ and $\mathrm{N} 7-\mathrm{H} 1 \mathrm{~N} \cdots 07=1.96 \AA$ (Figure 3 ). Selected bond lengths for the two crystallographic types of molecules are presented in Table S2 of the Supplementary Material. 

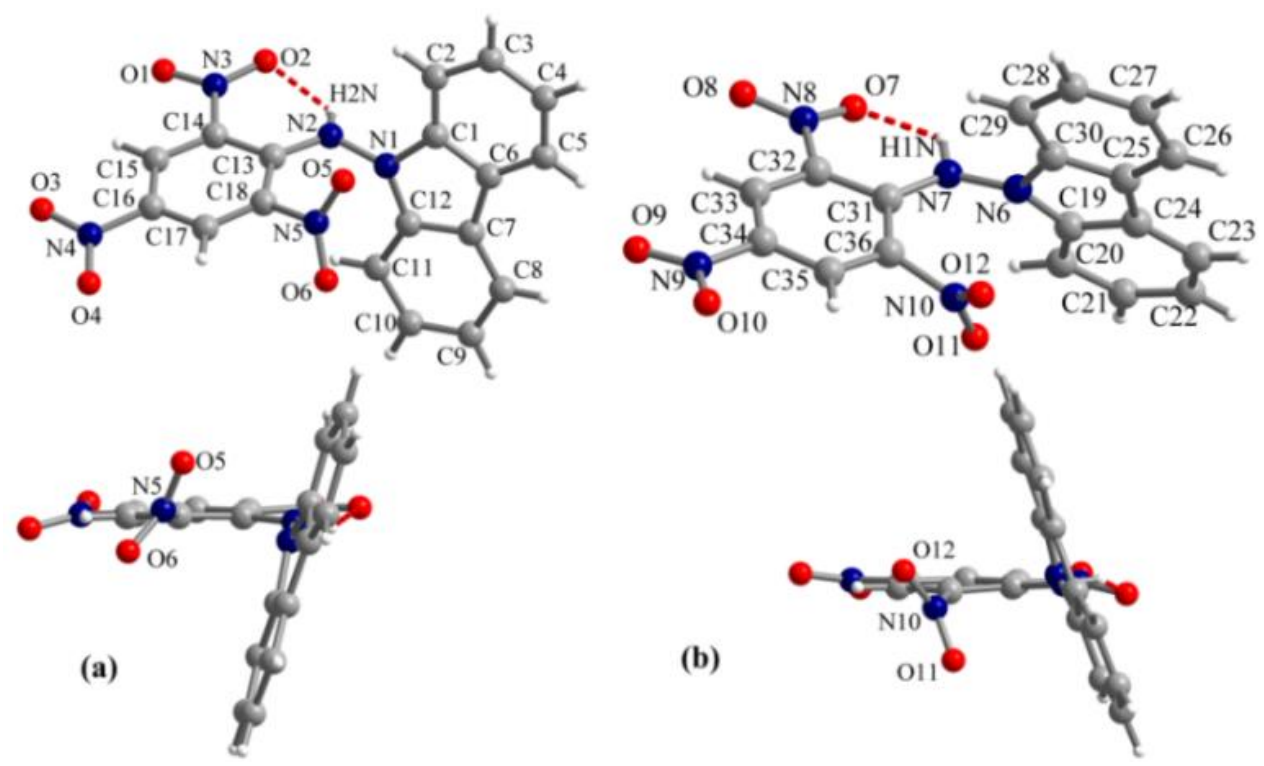

Figure 3. Perspective (up) and side (down) views of the two crystallographic molecules in crystalline $\mathbf{5 a .}$

\section{UV-Vis spectroscopy}

By oxidation of the compounds $\mathbf{1} \mathbf{a}-\mathbf{5} \mathbf{a}$, the persistent free radicals $\mathbf{1} \mathbf{b}-\mathbf{5} \mathbf{b}$ are obtained. In a similar way, in the presence of a base, compounds 1a-5a formed the corresponding anions 1c-5c (Figure 1). All these derivatives have different colors as can be deduced from Table 1 and the Supplementary Material (Figures S4 and S5).

Table 1. Physical and chemical characteristics of compounds 1-5

\begin{tabular}{|c|c|c|c|c|c|c|c|c|}
\hline & $\lambda_{\max }($ methanol, $\mathrm{nm})$ & $\mathrm{R}_{f}$ & $E_{o x}(V)$ & $\mathrm{pK}_{\mathrm{a}}$ & $\begin{array}{l}\mathrm{a}_{\mathrm{N} 1} / \mathrm{a}_{\mathrm{N} 2}{ }^{*} \\
\text { (Gauss) }\end{array}$ & $\begin{array}{c}\text { BDE } \\
\text { (kcal/mol) }\end{array}$ & $\log P^{\#}$ & $\mathrm{PSA}^{\#}$ \\
\hline $1 a$ & 267,337 & 0.26 & & 11.3 & & 74.5 & 5.04 & 106.91 \\
\hline $1 b$ & $512^{*}$ & & & & $9.49 / 6.63$ & & & \\
\hline 1c & $265,330,383$ (sh) & & 0.13 & & & & & \\
\hline $2 a$ & 287,363 (sh), 441 (sh) & 0.14 & & 10.7 & & 76.4 & 4.31 & 119.81 \\
\hline $2 b$ & $506^{*}$ & & & & $8.27 / 8.27$ & & & \\
\hline 2c & $312,396,441$ & & 0.25 & & & & & \\
\hline 3a & 321 & 0.19 & & 8.5 & & 75.3 & 4.93 & 152.74 \\
\hline $3 b$ & $528^{*}$ & & & & $9.59 / 7.88$ & & & \\
\hline $3 c$ & 323,431 & & 0.33 & & & & & \\
\hline $4 a$ & 268,346 (sh) & 0.24 & & 11.1 & & 76.3 & 8.20 & 122.18 \\
\hline $4 b$ & $500^{*}$ & & & & $9.24 / 6.91$ & & & \\
\hline 4c & 280,365 (sh) & & 0.61 & & & & & \\
\hline $5 a$ & 287,322 & 0.11 & & 8.7 & & 82 & 4.72 & 154.43 \\
\hline $5 b$ & $527^{*}$ & & & & $10.68 / 5.71$ & & & \\
\hline $5 c$ & $265,295,429$ & & 0.22 & & & & & \\
\hline
\end{tabular}

* in DCM; \# calculated (see Experimental); $\mathrm{R}_{\mathrm{f}}=$ retention factor; $\mathrm{E}_{\mathrm{ox}}=$ oxidation potential; $\mathrm{K}_{\mathrm{a}}=$ acidity constant; $\mathrm{a}_{\mathrm{N}}=$ hyperfine coupling constant; $\mathrm{BDE}=$ bond dissociation energy; $\mathrm{P}=$ partition coefficient; PSA=polar surface area. 
The $\mathrm{pK}_{\mathrm{a}}$ (acidity constant) values for compounds $\mathbf{3 a}$ and $\mathbf{5 a}$ were measured previously (in a mixture of methanol-water, 1/1). ${ }^{12,13}$ The $\mathrm{pK}_{\mathrm{a}}$ value of compound $\mathbf{1 a}$, measured in DMSO-water, is also in the literature. ${ }^{14}$ To allow the comparison of all, we evaluated $\mathbf{1 a}$ together with $\mathbf{2 a}$ and $\mathbf{4 a}$ again under the same conditions (see Experimental Section). The values obtained are also compiled in Table 2. Among all of the compounds, 3a and $5 a$ have similar acidity constants $\left(\mathrm{pK}_{\mathrm{a}} \sim 8.6\right)$, meaning the presence of the picryl moiety (the three nitro groups arranged in ortho, ortho' and para positions) influences most the hydrazine hydrogens and plays the most prominent role in their acidities.

\section{ESR, cyclic voltammetry (CV), and bond dissociation energy (BDE) values}

Compounds $\mathbf{1 b} \mathbf{b} \mathbf{5} \mathbf{b}$ are persistent free radicals that are best characterized by ESR spectroscopy. This technique allows, firstly, to provide evidence that a compound is a free radical. More information can be obtained by measuring the hyperfine coupling constants $\left(a_{N}\right)$. Hydrazyl free radicals are characterized by their two hyperfine coupling constants. In order to get an accurate value for these coupling constants, their spectra were simulated using WinSim software. ${ }^{15}$ The $\mathrm{a}_{\mathrm{N}}$ values are listed in Table 1 and the spectra are presented in Figure 4. A higher ratio between the two hyperfine coupling constants is noticed for compound $\mathbf{5 b}$. It has been reported that the aminocarbazolyl moiety induces such an effect, as compared with the diphenylamino moiety. ${ }^{16}$

Cyclic voltammetry is an electrochemical technique that allows a rapid and easy measurement of the redox (oxidation and reduction) potential of a chemical compound. One of our aims was to evaluate the oxidation potential $\left(E_{o x}\right)$ of the anions $\mathbf{1 c}-\mathbf{5} \mathbf{c}$. Following their one-electron oxidation, the free radicals $\mathbf{1} \mathbf{b}-\mathbf{5 b}$ are obtained (Figure S6, Supplementary Material). The values obtained, are presented in Table 1 . The second oxidation peak is due to the formation of the cation obtained following a second electron removal. The Supplementary Material section shows cyclic voltammograms for $1 \mathrm{mM}$ of $1 \mathrm{c}-5 \mathrm{c}$ in a $0.1 \mathrm{M}$ tetrabutylammonium hexafluorophosphate $\left(\mathrm{TBAPF}_{6}\right)$-acetonitrile solution containing $0.1 \mathrm{M}$ sodium ethoxide at different scan rates $(v)$, and the main parameters for the calculation of standard rate constants of $1 c-5 c$. The reversibility of the electro-oxidation process for $\mathbf{1 c}-\mathbf{5 c}$ to $\mathbf{1} \mathbf{b}-\mathbf{5} \mathbf{b}$ was good, thereby fulfilling all of the diagnostic criteria for reversible processes: $\left.\Delta E_{p}=E_{p a}-E_{p c}=59 / n m V ; E_{p}-E_{p / 2}=59 / n m V ; i_{p a} / i_{p c}=1, d\right) i_{p} \approx v^{1 / 2}$, and $E_{p}$ is independent of $v$. The meanings of the parameters are well known in the literature. The second electron transfer for all compounds is a quasi-reversible process. Their standard rate constants were calculated according to Nicholson's method ${ }^{17}$ and are listed in the Supplementary Material (Table S3). This method demonstrated that $E_{\mathrm{p}}$ is a function of the single dimensionless kinetic parameter (Equation 1):

$$
\Psi=\frac{\left(\frac{D_{O}}{D_{R}}\right)^{\alpha / 2} K^{0}}{\left(\pi D_{O} v F / R T\right)^{1 / 2}}
$$

where $\psi$ is dimensionless parameter, $D_{O}$ is the diffusion coefficient of the oxidative species and $D_{R}$ the diffusion coefficient of the reductive species, $\alpha$ is the charge transfer coefficient, $K^{0}$ is heterogeneous electron transfer rate constant, $v$ is scan rate of the potential, $n$ is the number of electrons transferred in the electrochemical reaction, $\mathrm{F}$ is the Faraday constant, $\mathrm{R}$ is the molar gas constant, and $\mathrm{T}$ is the absolute temperature.

After measuring the $E_{\mathrm{p}}$ value, the corresponding value of $\Psi$ is taken from the table of variation of $\Delta E_{p}$ with $\Psi$ at $25{ }^{\circ} \mathrm{C} .{ }^{18}$ The diffusion coefficients of oxidized and reduced species $\left(D_{O}\right.$ and $\left.D_{R}\right)$ are similar so $D_{O} / D_{R} \approx 1, D_{O}$ $=10^{-5} \mathrm{~cm}^{2} / \mathrm{s}, \mathrm{T}=298 \mathrm{~K}, \mathrm{~F}=9.6410^{4} \mathrm{C} / \mathrm{mol}, \mathrm{R}=8.314 \mathrm{~J} / \mathrm{mol} \mathrm{K}$. 


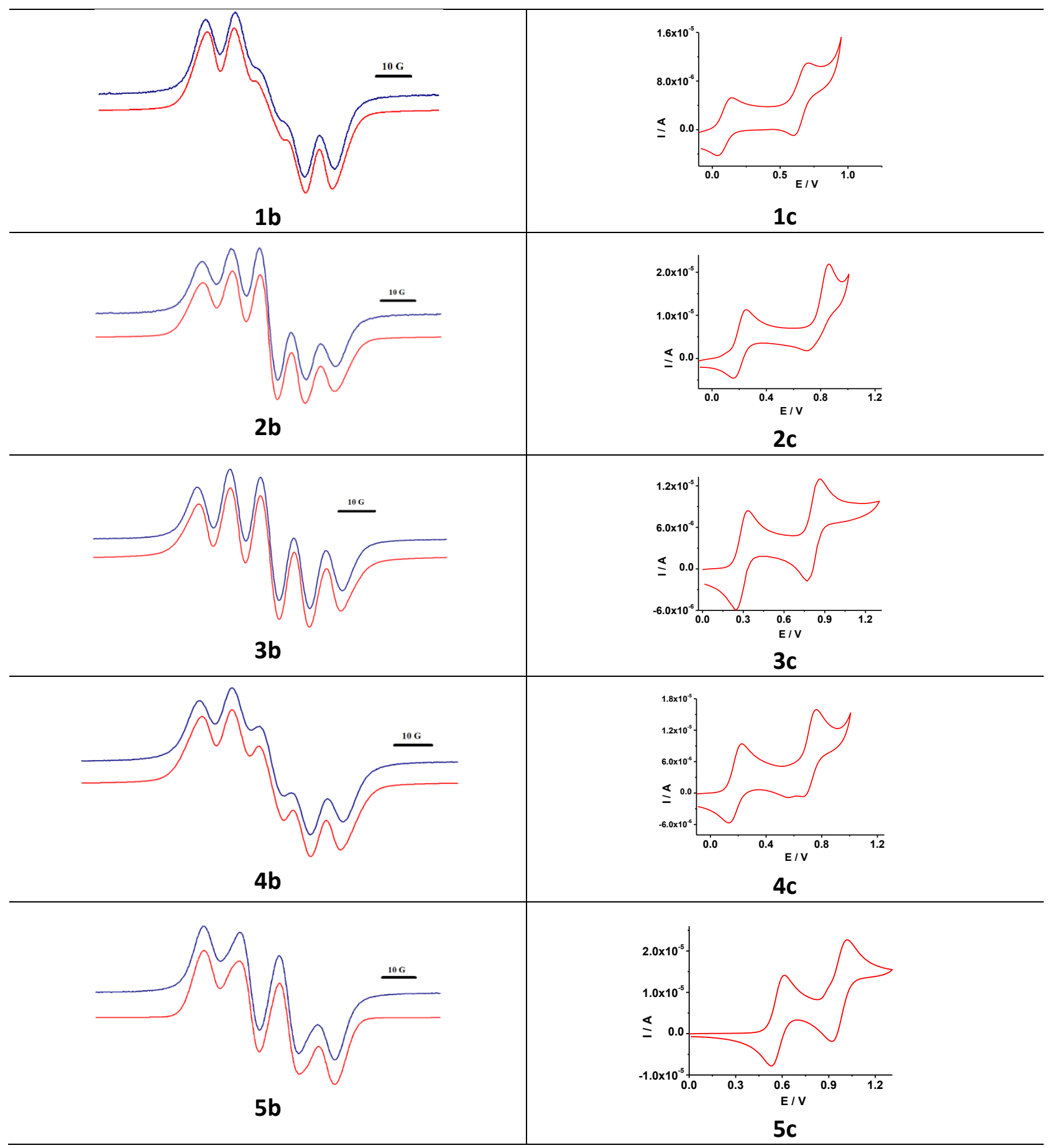

Figure 4. ESR spectra (left), of free radicals $\mathbf{1 b}-\mathbf{5 b}$ (experimental-blue, simulated-red), and CVs (right), of anions 1c-5c.

The bond dissociation energy (BDE) for a weak acid can be estimated using the following cycle that makes use of $\mathrm{pK}_{\mathrm{a}}$ and $\mathrm{E}_{\mathrm{ox}}$ values. ${ }^{19,20}$ Equation 2 is characterized by the $\mathrm{pK}_{\mathrm{a}}$ value while Equation 3 is characterized by the $E_{o x}$ value. Thus, the BDE can be estimated using Equation $4 .^{20}$

$$
{ }_{I} \mathrm{~N}-\mathrm{NH} \rightleftharpoons{ }_{/} \rightleftharpoons \mathrm{N}^{-}+\mathrm{H}^{+}
$$




$$
\begin{aligned}
& { }_{\mathrm{N}-\mathrm{N}^{-}} \rightleftharpoons \\
& B D E=1.37 p K_{a}+23.06 E_{o x}+56
\end{aligned}
$$

Calculations using the values presented in Table 2 afford values close to $75 \mathrm{kcal} / \mathrm{mol}$ for compounds $1 \mathrm{a}-\mathbf{4 a}$, while $5 \mathrm{a}$ has a value of $82 \mathrm{kcal} / \mathrm{mol}$. This is in agreement with the well-known strong oxidizing power of the radical $\mathbf{5 b} .^{6}$ This oxidation capability is also strongly correlated with the substituents. ${ }^{21-23}$

\section{LogP and PSA}

Partition coefficient (P) and polar surface area (PSA) are generally considered two of the most important parameters in the biological evaluation of a chemical compound. ${ }^{24,25}$ The partition coefficient between a water phase and a non-miscible phase is usually shown as logP ( $n$-octanol is used mainly as the lipidic phase). Because there is now plenty of software available that can instantly calculate many molecular properties, we employed a program in this study that allowed such calculations based on group contributions. ${ }^{26}$ This software allows an easy calculation of molecular properties which are useful for structure-activity QSAR studies. Values obtained are also compiled in Table 1. As can be seen, compound $\mathbf{4 a}$ has the highest hydrophobicity, while $\mathbf{5 a}$ has the highest PSA.

\section{Conclusions}

Five hydrazine derivatives (1a-5a) were studied together with their corresponding persistent free radicals (1b5b) and their anions (1c-5c). Compound 4a was synthesized for the first time and structurally characterized. The crystal X-ray structure was obtained for compound 5a. For all of the compounds (as appropriate), UV-Vis, ESR spectroscopy and cyclic-voltammetry measurements were used to confirm their acid-base and redoxpotential behaviors. Bond dissociation energies (BDE) were calculated using $\mathrm{pK}_{\mathrm{a}}$ and $\mathrm{E}_{\mathrm{ox}}$ values.

\section{Experimental Section}

\section{General}

Instrumentation. UV-Vis spectra were recorded in methanol or DCM at ambient temperature on a dual beam UVD-3500 spectrometer. IR spectra were recorded on an FT-IR Bruker Vertex 70 spectrometer. ESR spectra were recorded in DCM, at room temperature, using a JEOL FA100 spectrometer. ${ }^{1} \mathrm{H}$ - and ${ }^{13} \mathrm{C}-\mathrm{NMR}$ spectra were recorded on Bruker Fourier 300 or $500 \mathrm{MHz}$ instruments, respectively, at room temperature, using deuterated chloroform as the solvent. The solvent signals were used as an internal standard for calibration. $X$ ray diffraction measurements were performed on a STOE IPDS II diffractometer, operating with Mo $K_{\alpha}$ ( $\lambda=$ $0.71073 \AA$ ) $X$-ray tube with graphite monochromator. The structure was solved by direct methods (using SHELXS-2013 crystallographic software) and refined by full-matrix least-squares techniques based on $F^{2}$. The non- $\mathrm{H}$ atoms were refined with anisotropic displacement parameters. Calculations were performed using a SHELXL-2018 crystallographic software package. A summary of the crystallographic data and the structure refinement for crystal 5a are given in Tables S1 and S2 (Supplementary Material file). CCDC reference number: 1954892. Cyclic voltammograms were recorded in organic solution of acetonitrile with 0.1M TBAPF 6 
(tetrabutylammonium hexafluorophosphate) as supporting electrolyte containing $0.1 \mathrm{M}$ sodium ethoxide at 50 $\mathrm{mV} / \mathrm{s}$ scan rate. All electrochemical measurements were performed using a potentiostat/galvanostat Autolab $302 \mathrm{~N}$ connected to a PC running the software GPES. The electrochemical cell used was compartmentalized with a three-electrode system, a Pt disk electrode as working electrode, a glassy carbon rod as the auxiliary electrode, and a $\mathrm{Ag} / \mathrm{AgCl}$ electrode as reference electrode.

All software used in the simulation of the ESR spectra and calculations of logP and PSA are freely available. ESR spectra were simulated using the WinSim software. ${ }^{15} \log P$ and PSA values were calculated using the Molinspiration software. ${ }^{23}$

Materials and procedures. All chemicals, materials and solvents were purchased from Sigma-Aldrich or Chimopar and used as received. Compounds $\mathbf{1 a}-\mathbf{3 a}$ and $\mathbf{5 a}$ were synthesized according to the literature. ${ }^{19}$ Free radicals $\mathbf{1 b}-\mathbf{5} \mathbf{b}$ were obtained by oxidation of compounds $\mathbf{1 a - 5 a}$ with lead dioxide in DCM (10 mg of each compound dissolved in $10 \mathrm{~mL}$ of DCM and stirred at room temperature with about $0.5 \mathrm{~g}$ of lead dioxide for 5 min, then filtered off and used as required). Compounds 1c-5c were obtained by adding compounds 1a-5a dissolved in methanol to a solution of potassium hydroxide in methanol ( $2 \mathrm{mg}$ of each compound dissolved in $8 \mathrm{~mL}$ methanol were added $2 \mathrm{~mL}$ of a solution of potassium hydroxide in methanol).

All compounds were obtained in a very similar way. If required, compounds can be purified by flash-column chromatography on silica gel using a mixture of DCM-hexane as eluent. $\mathrm{R}_{f}$ (retention factor) values were measured on silica gel TLC plates using a mixture of DCM/hexane (1/1 v/v as eluent).

2-[5-(2,2-Diphenylhydrazino)-2,4-dinitrophenyl]-1,1-diphenylhydrazine (4a). To a solution of 1,5-difluoro-2,4dinitrobenzene $(0.2 \mathrm{~g}, 1 \mathrm{mmol})$ dissolved in ethanol $(30 \mathrm{~mL})$ was added 1,1-diphenylhydrazine hydrochloride $(0.5 \mathrm{~g}, 2.2 \mathrm{mmol})$ and sodium hydrogen carbonate $(4 \mathrm{~g}, 48 \mathrm{mmol})$; the mixture was heated to reflux for $1 \mathrm{~h}$. The hot solution was filtered (the solid can be washed with DCM (50 mL) if the compound precipitates). The desired compound was isolated in a few ways: i) cooling overnight, it separates as a precipitate, ii) adding water (in either case followed by filtration); or iii) by adding water and extraction with DCM ( $3 \times 50 \mathrm{~mL}$ ). The precipitate was allowed to dry at room temperature. If DCM was used, the solvent was removed by a rotavap. Purification can be performed by flash column chromatography or preparative TLC, using silica gel as stationary phase and hexane/DCM as eluent, resulting a yellow solid ( $230 \mathrm{mg}, 44 \%) ; \mathrm{mp} 176^{\circ} \mathrm{C} .{ }^{1} \mathrm{H}-\mathrm{NMR}(300$ $\left.\mathrm{MHz}_{2} \mathrm{CDCl}_{3}\right): \delta_{\mathrm{H}} 9.95(2 \mathrm{H}, \mathrm{s}, 2 \mathrm{NH}), 9.09\left(1 \mathrm{H}, \mathrm{s}, \mathrm{ArNO}_{2}\right) ; 9.06\left(1 \mathrm{H}, \mathrm{s}, \mathrm{ArNO}_{2}\right), 7.32-7.2(8 \mathrm{H}, \mathrm{m}$, phenyl), 7.11-7.07 $\left(12 \mathrm{H}, \mathrm{m}\right.$, phenyl). ${ }^{13} \mathrm{C}-\mathrm{NMR}\left(75 \mathrm{MHz}, \mathrm{CDCl}_{3}\right): \delta_{\mathrm{C}} 162.3,158.7,150,145,129.8,127.7,127,124.8,119.7,102.8$, 102.4. IR: $v_{\max }\left(\mathrm{KBr}, \mathrm{cm}^{-1}\right): 3312,3087,2956,1631,1584,1489,1326,1293,1255,1074,1018,790,757,692$, 532. Analysis: calc. for $\mathrm{C}_{30} \mathrm{H}_{24} \mathrm{~N}_{6} \mathrm{O}_{4} \mathrm{MW} 532$ : $\mathrm{C}, 67.67 ; \mathrm{H}, 4.51 ; \mathrm{N}, 15.79$; found: $\mathrm{C}, 67.51, \mathrm{H}, 4.73 ; \mathrm{N}, 15.66 \%$.

\section{NMR data of hydrazines 1a-3a, 5a}

1,1-Diphenyl-2-(2,4-dinitrophenyl)hydrazine (1a). ${ }^{1} \mathrm{H}-\mathrm{NMR}\left(500 \mathrm{MHz}, \mathrm{CDCl}_{3}\right): \delta_{\mathrm{H}} 10.05(1 \mathrm{H}, \mathrm{s}, \mathrm{NH}), 9.16(1 \mathrm{H}, \mathrm{d}$, $\left.{ }^{4} J_{H H} 5 \mathrm{~Hz}, \mathrm{ArNO}_{2}\right) ; 8.28\left(1 \mathrm{H}, \mathrm{dd},{ }^{3} \mathrm{~J}_{H H} 10 \mathrm{~Hz},{ }^{4} J_{H H} 5 \mathrm{~Hz}, \operatorname{ArNO}_{2}\right), 7.58\left(1 \mathrm{H}, \mathrm{d}^{3}{ }^{3} J_{H H} 10 \mathrm{~Hz}, \operatorname{ArNO}_{2}\right), 7.36-7.33(4 \mathrm{H}, \mathrm{m}$, phenyl), 7.19-7.11 (6H, m, phenyl). ${ }^{13} \mathrm{C}-\mathrm{NMR}\left(125 \mathrm{MHz}, \mathrm{CDCl}_{3}\right): \delta_{\mathrm{C}} 148.8,145.2,138.4,130.5,124.5,123.8$, $119.5,115.2$.

1,1-Diphenyl-2-(3,5-dinitropyridin-2-yl)hydrazine (2a). ${ }^{1} \mathrm{H}-\mathrm{NMR}\left(300 \mathrm{MHz}_{\mathrm{CDCl}}\right): \delta_{\mathrm{H}} 10.37(1 \mathrm{H}, \mathrm{s}, \mathrm{NH}) ; 9.27$ $\left(2 \mathrm{H}, \mathrm{m}, \mathrm{ArNO}_{2}\right) ; 7.34-7,29\left(4 \mathrm{H}, \mathrm{m}\right.$, phenyl); $7.18\left(4 \mathrm{H}, \mathrm{m}\right.$, phenyl); $7.08\left(2 \mathrm{H}, \mathrm{m}\right.$, phenyl). ${ }^{13} \mathrm{C}-\mathrm{NMR}(75 \mathrm{MHz}$, $\left.\mathrm{CDCl}_{3}\right): \delta_{\mathrm{C}} 154.8 ; 151.4 ; 145 ; 136.2 ; 131.6 ; 129.4 ; 126.9 ; 123.8 ; 119.5$.

1,1-Diphenyl-2-(2,4,6-trinitrophenyl)hydrazine (3a). ${ }^{1} \mathrm{H}-\mathrm{NMR}\left(300 \mathrm{MHz}, \mathrm{CDCl}_{3}\right): \delta_{\mathrm{H}} 10.13(1 \mathrm{H}, \mathrm{s}, \mathrm{NH}), 9.21(1 \mathrm{H}$, $\left.\mathrm{s}, \mathrm{ArNO}_{2}\right) ; 8.50\left(1 \mathrm{H}, \mathrm{s}, \mathrm{ArNO}_{2}\right), 7.38-7.33(4 \mathrm{H}, \mathrm{m}$, phenyl), 7.18-7.23 (2H, m, phenyl), 7.13-7.10 (4H, m, phenyl).

${ }^{13} \mathrm{C}-\mathrm{NMR}\left(75 \mathrm{MHz}, \mathrm{CDCl}_{3}\right)$ : 回 $146,142,136.5,129.6,125.9,120.5$. 
9-[(2,4,6-Trinitrophenyl)amino]carbazole(5a). ${ }^{1} \mathrm{H}-\mathrm{NMR}\left(300 \mathrm{MHz}, \mathrm{CDCl}_{3}\right): \delta_{\mathrm{H}} 10.37(1 \mathrm{H}, \mathrm{s}, \mathrm{NH}), 9.40(1 \mathrm{H}, \mathrm{s}$, $\left.\operatorname{ArNO}_{2}\right) ; 8.45\left(1 \mathrm{H}, \mathrm{s}, \mathrm{ArNO}_{2}\right), 8.02\left(2 \mathrm{H}, \mathrm{d},{ }^{3} \mathrm{~J}_{H H} 9 \mathrm{~Hz}\right.$, carbazole), $7.46\left(2 \mathrm{H}, \mathrm{t},{ }^{3} \mathrm{~J}_{H H} 9 \mathrm{~Hz}, \mathrm{carbazole}\right), 7.37\left(2 \mathrm{H}, \mathrm{t},{ }^{3} \mathrm{~J}_{H H}\right.$ $9 \mathrm{~Hz}$, carbazole), $7.26\left(2 \mathrm{H}, \mathrm{m}\right.$, carbazole). ${ }^{13} \mathrm{C}-\mathrm{NMR}\left(75 \mathrm{MHz}, \mathrm{CDCl}_{3}\right): \delta_{\mathrm{C}} 142.1,140.4,139.8,137.6,133.6,126.2$, $125,123.0,121.0,109.3$.

\section{Supplementary Material}

The Supplementary Material file can be found in the online version. It contains the X-ray crystallographic data and structure refinement details, and spectral traces for compound 5a; UV/Vis of all compounds and ions 1-5, ESR of 1b-5b; cyclic voltammograms of $\mathbf{1 c}-\mathbf{5 c}$.

\section{Acknowledgements}

This work was supported by a grant of Ministry of Research and Innovation, CNCS -UEFISCDI, project number PN-III-P4-ID-PCE-2016-0187, within PNCDI III.

\section{References}

1. Forrester, A.R.; Hay, J.M.; Thomson, R.H. Organic Chemistry of Stable Free Radicals. Academic: New York, 1968; pp 137-173.

2. Hicks, R. Stable Radicals: Fundamentals and Applied Aspects of Odd-Electron Compounds. Wiley: New York, 2010; pp 7, 216, 246-273, 547-563.

3. Tudose, M.; Angelescu, D.; Ionita, G.; Caproiu, M. T.; Ionita, P. Lett. Org. Chem.2010, 7,182-185. https://doi:10.2174/157017810790796309

4. Ionita, P. Let. Org. Chem. 2008, 5, 42-46. https://doi:10.2174/157017808783330144

5. Ionita, P. Free Radical Res. 2006, 40, 59-65. https://doi:10.1080/10715760500385699

6. Brown, K. C.; Weil, J. A. Can. J. Chem.1986, 64, 1836-1838. https://doi:10.1080/10715760500385699

7. Gubanov, V. A.; Pereliaeva, L. A.; Chirkov, A. K.; Yastchenko, G. N.; Matevosian, R. O. Int. J. Quantum Chem. 1971, 5, 513-524. https://doi:10.1002/qua.560050505

8. Ionita, P. Chem. Papers 2005, 59, 11-16.

9. Prior, R.L.; Wu, X.; Schaich, K. J. Agric. Food Chem. 2005, 53, 4290-4302. https://doi:10.1021/if0502698

10. Shakir, A.; Madalan, A. M.; Ionita, G.; Lupu, S.; Lete, C.; lonita, P. Chem. Phys. 2017, 490, 7-11. https://doi:10.1016/i.chemphys.2017.03.011

11. Wang, H.; Barton, R. J.; Robertson, B. E.; Weil, A.J.; Brown, K. C. Can. J. Chem. 1987, 65, 1322-1326. https://doi:10.1139/v87-221 
12. Luca, C.; Ionita,P.; Constantinescu, T. Rev. Roum. Chim.1994, 39, 1141-1149.

13. Ionita, P.; Caproiu, M. T.; Meghea, A.; Maior, O.; Rovinaru, M.; Ionita, G. Polish J. Chem. 1999, 73, $1177-$ 1183.

14. Bordwell, F. G.; Cheng, J. P.; Harrelson, J. A. J. Am. Chem. Soc. 1988, 110, 1229-1231. https://doi:10.1021/ja00212a035

15. https://www.niehs.nih.gov/research/resources/software/tox-pharm/tools/index.cfm

16. Duffy, W. Jr.; Strandburg, D. L. J. Chem. Phys. 1967, 46, 456-464.

17. Nicholson, R. S. Analytical Chem. 1965, 35, 1351-1355.

https://doi:10.1021/ac60230a016

18. Zoski, C. G. Handbook of Electrochemistry, New Mexico, USA, Elsevier, 2007.

19. Stanciuc, G.; Zarna, N.; Spataru, N.; Constantinescu, T. Rev. Roum. Chim. 1996, 41, 755-761.

20. Bordwell, F. G.; Zhang, X. M. Acc.Chem. Res. 1993, 26, 510-517.

https://doi:10.1021/ar00033a009

21. Hristea, E. N.; Bem, M.; Balaban, T. S.; Eichhöfer, A.; Caproiu, M. T.; Draghici, C.; Ionita, G.; Spataru, T.; Enache, C.; Maganu, M.; Beteringhe, A.; Hillebrand, M.; Constantinescu, T.; Balaban, A. T. Arkivoc 2011, xi, 198-221.

https://doi:10.3998/ark.5550190.0012.b19

22. Balaban, A. T.; Constantinescu, T.; Caproiu, M. T.; Giorgi, M.; Balaban, T. S. Z. Naturforsch. B 2017, 72, 8994.

https://doi:10.3998/ark.5550190.0012.b19

23. Baratoiu, R. D.; Bem, M.; Radutiu, A. C.; Spataru, T.; Radu, M. M.; Voicescu, M.; Ionita, G.; Stanica, N.; Constantinescu, T.; Balaban, A. T. Monatsh. Chem. 2017, 148, 1411-1416.

https://doi:10.1007/s00706-017-2009-6

24. Leo, A.; Hansch, C.; Elkis, D. Chem. Rev. 1971, 71, 525-616.

https://doi:10.1021/cr60274a001

25. Sobańska, A.; Wanat, K.; Brzezińska, E. Open Chem. 2019, 17, 43-56.

https://doi:10.1515/chem-2019-0005

26. https://www.molinspiration.com 